\title{
Method for increasing $\beta$-SiC yield on solid state reaction of coal fly ash and activated carbon powder
}

\author{
SULARDJAKA*, JAMASRI, M W WILDAN and KUSNANTO ${ }^{\dagger}$ \\ Department of Mechanical and Industrial Engineering, Gadjah Mada University, \\ Yogyakarta 55281, Indonesia \\ ${ }^{\dagger}$ Department of Engineering Physics, Gadjah Mada University, Yogyakarta 55281, Indonesia
}

MS received 18 March 2010; revised 27 April 2010

\begin{abstract}
A novel process for increasing $\beta$-SiC yield on solid state reaction of coal fly ash and micro powder activated carbon powder has been proposed. $\beta$-SiC powder was synthesized at temperature $1300^{\circ} \mathrm{C}$ for $2 \mathrm{~h}$ under vacuum condition with $1 \mathrm{l} / \mathrm{min}$ argon flow. Cycling synthesis process has been developed for increasing $\beta$-SiC yield on solid state reaction of coal fly ash and activated carbon powder. Synthesized products were analyzed by XRD with $\mathrm{Cu}-\mathrm{K} \alpha$ radiation, FTIR spectrometer and SEM fitted with EDAX. The results show that the amount of relative $\beta-\mathrm{SiC}$ is increased with the number of cycling synthesis.
\end{abstract}

Keywords. SiC; cycling synthesis; solid state reaction.

\section{Introduction}

Fly ash, a waste product of coal combustion in thermal power plants, is produced in dry form in large quantity. Large quantities of fly ash are produced during the combustion of coal in the production of electricity. Coal combustion by product in USA and EU is estimated around 115 million tons per year (Querol et al 2002). Suralaya power plant in Indonesia which is fueled by coal, has generated about 0.2 million tons fly ash in 2005 (Sulardjaka et al 2009). In South Africa, where high content coal is used in power generation, 24 million ton fly ash were produced in 1997, and only $5 \%$ of this ash was reused (Woolard et al 2000). The current annual production of worldwide coal ash is estimated around 600 millions tons, with fly ash constituting about 500 millions tons (Hongjie et al 2001). Most of the fly ash production is still stored in a disposal site and only $20-30 \%$ is reused as a valuable resource (Joshi and Lothia 1997). The amount of the fly ash released by factories and thermal power plants has been increasing throughout the world, and the disposal of fly ash has become a serious environmental problem. The compositions of the fly ash varies depending on the source of coal and the combustion process. The main constituents are metal oxides, predominantly of silicon and aluminum in addition to other metal oxides. Utilization of fly ash in producing novel materials, waste management and recovery of metals are the new research areas that will expand the positive reuse

\footnotetext{
*Author for correspondence (s_djaka@yahoo.com)
}

of this abundant material, thereby helping to reduce the environmental and economical impacts of its disposal.

Silicon Carbide ( $\mathrm{SiC}$ ) has superior strength and corrosion resistance at elevated temperature (Ryu et al 2002). In industrial scale, $\mathrm{SiC}$ is produced by the Acheon process, that is carbothermal reduction of silica sand with green petroleum coke in temperature of around $2400^{\circ} \mathrm{C}$ (Hongjie at al 2001). The carbothermal reduction is relatively simple and time-cost effective technique; in this process, mixture of carbon and silica or silicon is heated in a reactor in an inert atmosphere (Shi et al 2006). In order to optimize the production of $\mathrm{SiC}$ particles, several authors have proposed methods which used fine starting materials and reaction mixtures prepared by sol-gel techniques (Russell-Floyd et al 1993; Qiang Jin and Yun Go 2003; Shi et al 2006). Synthesis of $\mathrm{SiC}$ requires a series of reaction. At reaction temperature below $\sim 1400^{\circ} \mathrm{C}$, most of the $\mathrm{SiC}$ is generated through reaction solid $\mathrm{SiO}_{2}$ and solid carbon (Krstic 1992; Qian 2004). The reaction takes place at the contact point between solid carbon and solid $\mathrm{SiO}_{2}$. Fabrication of silicon carbide at low temperature needs long time, because it is limited by the diffusion rate of $\mathrm{SiO}_{2}$ and $\mathrm{C}$ (Krstic 1992).

The component of fly ash is $40 \%$ wt. $\mathrm{SiO}_{2}$. It is potential $\mathrm{SiO}_{2}$ resources on carbothermal reduction process. Quartz $\left(\mathrm{SiO}_{2}\right)$ and $\mathrm{SiO}$ can be reacted with activated carbon powder in carbothermal reduction process to produce silicon carbide. $\beta$-SiC powder had been successfully synthesized from fly ash and 8.21 $\mu \mathrm{m}$ carbon black (Hongjie et al 2001). Our previous work is also successful in synthesizing $\beta$-SiC form fly ash and $32 \mu \mathrm{m}$ activated carbon at temperature $1300^{\circ} \mathrm{C}$ under argon flow (Sulardjaka et al 
Table 1. Composition of Suralaya coal fly ash.

\begin{tabular}{lccccccccc}
\hline Compound & $\mathrm{SiO}_{2}$ & $\mathrm{Al}_{2} \mathrm{O}_{3}$ & $\mathrm{Fe}_{2} \mathrm{O}_{3}$ & $\mathrm{CaO}$ & $\mathrm{MgO}$ & $\mathrm{Na}_{2} \mathrm{O}$ & $\mathrm{MnO}$ & $\mathrm{K}_{2} \mathrm{O}$ & Others \\
\hline Weight & 45.51 & 30.35 & 8.71 & 5.49 & 2.75 & 1.45 & 0.1 & 0.64 & 5.0 \\
\hline
\end{tabular}

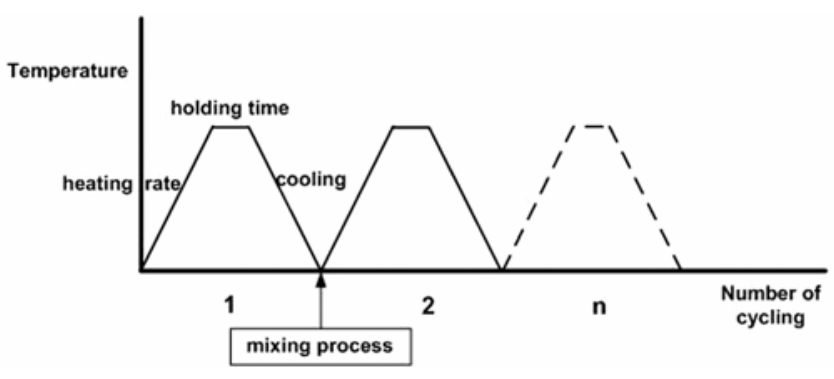

Figure 1. Schematic cycling synthesis.

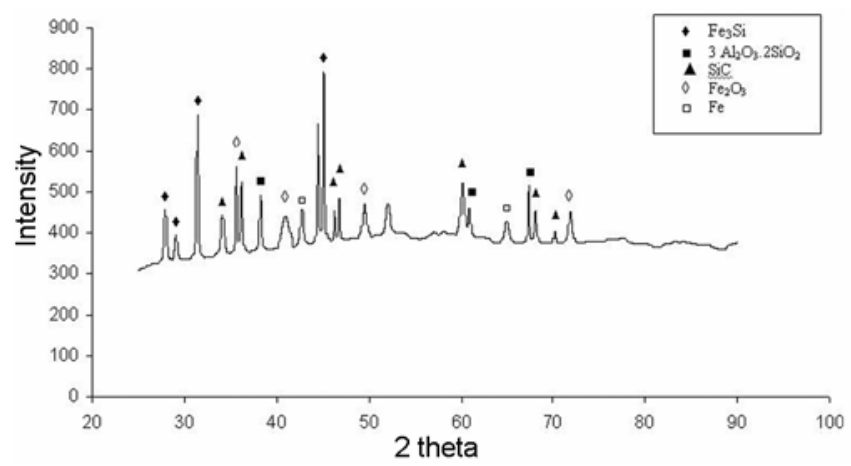

Figure 2. XRD pattern at reaction temperature $1300^{\circ} \mathrm{C}$ for $2 \mathrm{~h}$.

2009). SiC yield from synthesis process can be increased by increasing temperature, use very fine starting material and longer holding time reaction. However, those methods need higher cost process. Therefore, this paper proposes a method for increasing $\mathrm{SiC}$ yield at low temperature synthesis process, shorter holding time and utilizing cheap materials for synthesis $\beta$-SiC powder.

\section{Materials and experimental procedure}

Our experiment used starting materials which ultilized fly ash and activated carbon powder. The fly ash was collected from Suralaya power plant, Indonesia. Composition of the coal fly ash was analyzed by atomic absorption spectroscopy (AAS) as shown in table 1 .

Activated-carbon powder with particle size - 400 mesh $(<32 \mu \mathrm{m})$ was used as the carbon sources. The carbon source was made from granular activated-carbon that was ball milled and sieved with -400 mesh sieving machine. Weight of the fly ash in starting precursor was determined based on the amount of $\mathrm{SiO}_{2}$ in the fly ash. Molar ratio of $\mathrm{SiO}_{2}$ and activated-carbon powders was $1: 4$. The fly ash and activated carbon powder were mixed using magnetic stirrer for $6 \mathrm{~h}$ in ethanol solution.

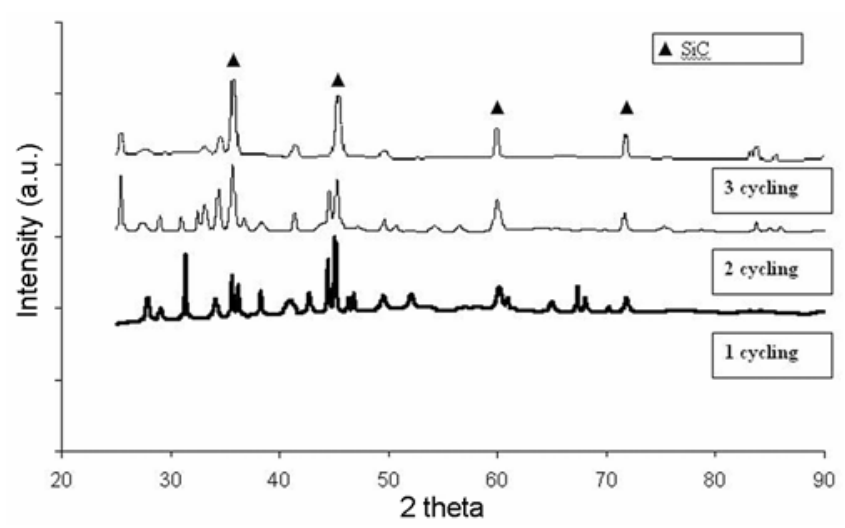

Figure 3. XRD pattern at reaction temperature 1300 for $2 \mathrm{~h}$ with cycling process.

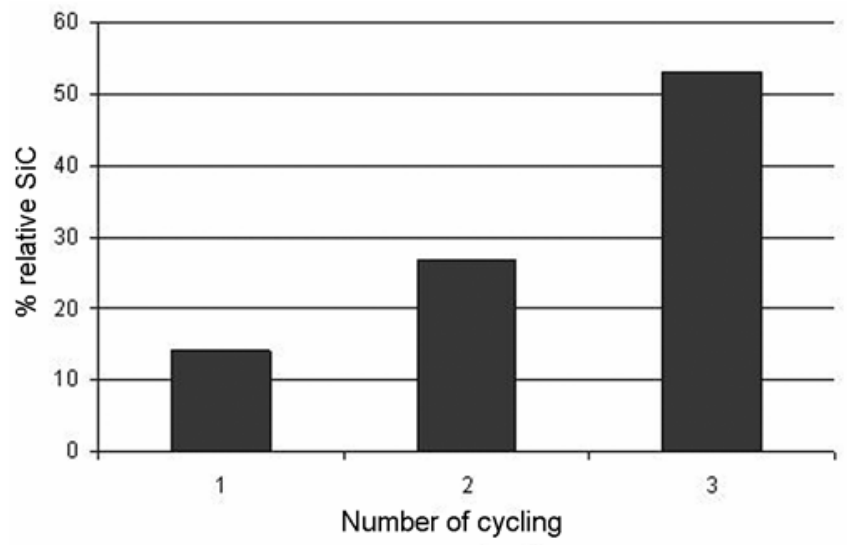

Figure 4. The effect of cycling on percentage of $\mathrm{SiC}$ yield

Synthesis of $\beta$-SiC was conducted in the carbolite vacuum furnace at temperature of $1300^{\circ} \mathrm{C}$, with a heating rate of $10^{\circ} \mathrm{C} /$ minute, and holding time process of $2 \mathrm{~h}$, then followed cooling in the furnace by switching the furnace off. All synthesis reactions were carried out on vacuum condition under $1 \mathrm{l} / \mathrm{min}$ argon flow. After the synthesis process, the product was heated at temperature $850^{\circ} \mathrm{C}$ for $4 \mathrm{~h}$ in atmosphere condition to burn the excess carbon. Synthesized products were examined by X-ray powder diffraction (XRD) using $\mathrm{CuK} \alpha$ radiation, Fourier transformation infrared spectrometer (FTIR) and SEM fitted with EDAX. Peaks obtain from XRD test were interpreted by PANalytical. The amount of $\beta$-SiC yield in each process was estimated by comparing the relative height of the $\beta$-SiC diffraction peaks with that of all diffraction peaks. Cycling synthesis process has been developed for increasing $\mathrm{SiC}$ yield at temperature synthesis 

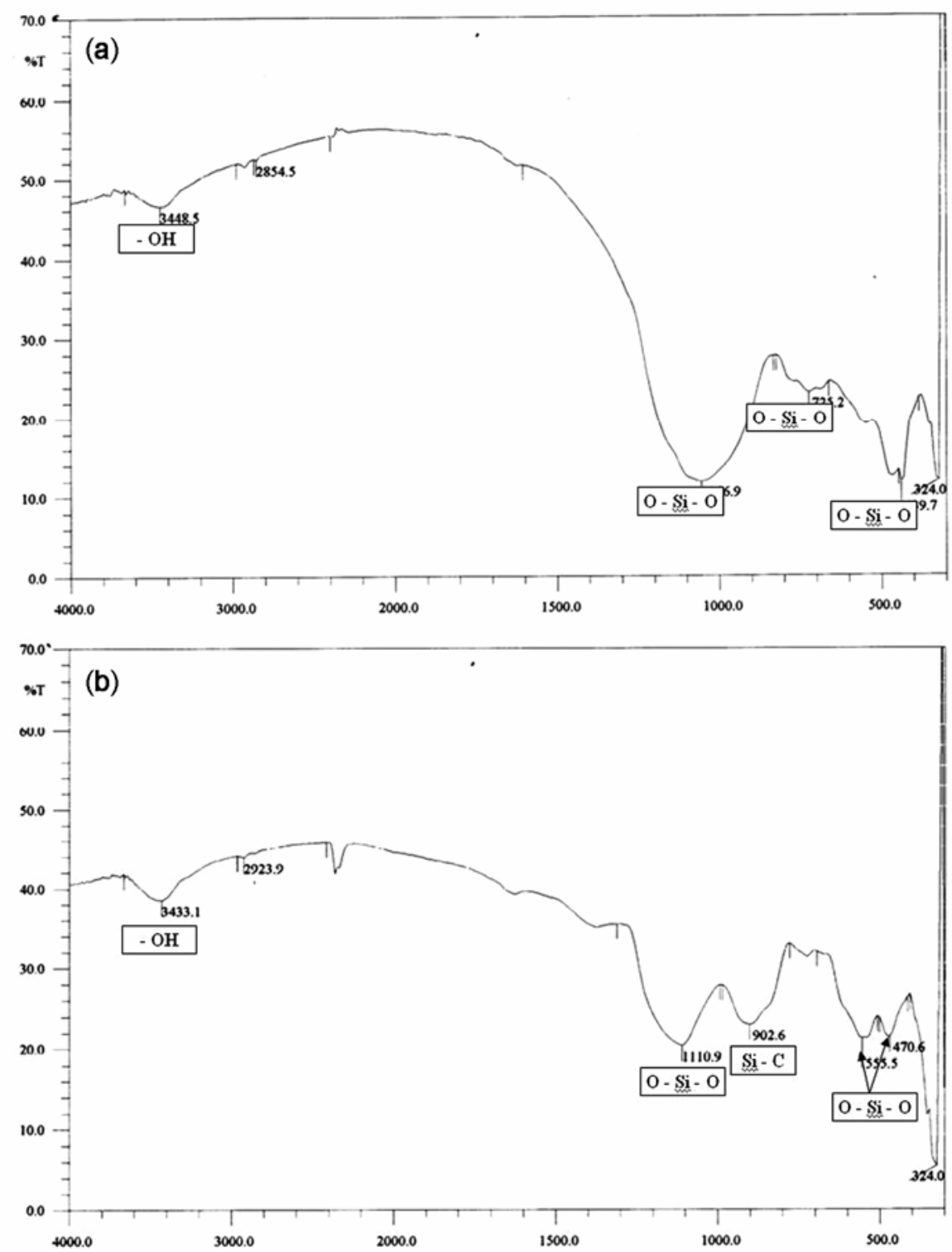

Figure 5. FTIR spectrum of fly ash (a) and synthesis product (b).

$1300^{\circ} \mathrm{C}$. The objective of the cycling process is to make new surface contact between $\mathrm{SiO}_{2}$ and $\mathrm{C}$. The cycling process is resynthesis of the product from previous synthesis process, the schematic of cycling synthesis is shown on figure 1 . After one cycling synthesis process, the synthesized product was added with 1 mol activated carbon powder then cruised and mixed on jar mill with steel ball for $2 \mathrm{~h}$.

\section{Results and discussion}

Figure 2 shows the XRD pattern synthesized product at temperature $1300^{\circ} \mathrm{C}$ from which $\beta$-SiC was formed by present major peaks at $35.6^{\circ}, 41 \cdot 3^{\circ}, 60 \cdot 1^{\circ}$ and $72 \cdot 1^{\circ}$.

Figure 3 shows the XRD pattern of the powders produced at $1300^{\circ} \mathrm{C}$ with the cycling process. It shows that peaks at $2 \theta=35 \cdot 6^{\circ}, 41 \cdot 3^{\circ}, 60 \cdot 1^{\circ}$ and $72 \cdot 1^{\circ}$ is higher with the increasing of the cycling process. This increase affects the relative amount of $\beta-\mathrm{SiC}$ as depicted in figure 4. Figures 3 and 4 show that $\mathrm{SiC}$ yield increases with the cycling process. Under the experimental condition of the present work, the reaction between $\mathrm{C}$ and $\mathrm{SiO}_{2}$ for producing $\mathrm{SiC}$ is shown in reaction (1) (Vix-Gutherl and Ehrburger 1997). At low temperature reaction (below $1400^{\circ} \mathrm{C}$ ) most of $\mathrm{SiC}$ formation is generated through reaction (1). The reaction consists of a solid-solid, solidliquid types reaction between $\mathrm{C}$ and $\mathrm{SiO}_{2}$. At this reaction, formation of $\beta-\mathrm{SiC}$ is formed by diffusion of $\mathrm{SiO}_{2}$ and $\mathrm{C}$ which takes place at the contact points between solid $\mathrm{C}$ and $\mathrm{SiO}_{2}$ (Krstic 1992; Russell-Floyd 1993). The cycling synthesis process requires mixing process between one and another previous synthesis process and produces new contact point between $\mathrm{SiO}_{2}$ and $\mathrm{C}$ and promote the diffusion rate. 

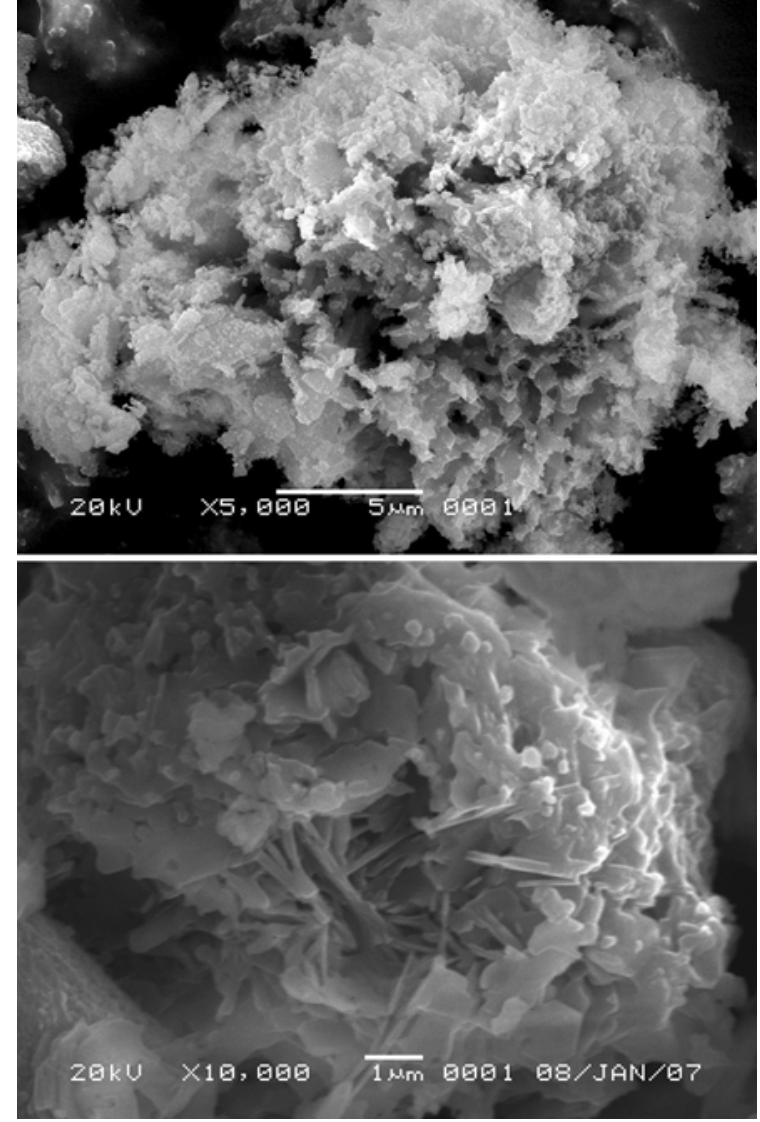

Figure 6. The $\mathrm{SiC}$ morphology.

In this research, there are possibility of two mechanisms that produce $\beta$-SiC. First, $\beta$-SiC is produced through mechanism diffusion process that follows (1), and second, $\beta$-SiC resulted through reaction (3) that involves catalyst of $\mathrm{Fe}_{2} \mathrm{O}_{3} . \quad \mathrm{Fe}_{2} \mathrm{O}_{3}$ acts as catalyst in resulting intermetallic phase $\left(\mathrm{Fe}_{3} \mathrm{Si}\right)$ as an intermediate phase as presented in figure 2. The presence of $\mathrm{Fe}_{3} \mathrm{Si}$ in this process makes possibility to obtain $\beta$ - $\mathrm{SiC}$ at temperature reaction under $1500^{\circ} \mathrm{C}$. In uncatalyzed reaction, silicon monoxide reacts with carbon to produce $\mathrm{SiC}$ as shown in reaction (2). In a catalyzed reaction, the possible explanations of the role of the catalyst $\mathrm{Fe}_{2} \mathrm{O}_{3}$ is (Narciso-Romero and Rodriguez-Reinoso 1996; Hongjie et al 2001): $\mathrm{Fe}_{2} \mathrm{O}_{3}$ produces a local decrease of $\mathrm{CO}$ produced because the metal oxide favours a disproportionate $\mathrm{CO}$ to give the $\mathrm{CO}_{2}$, the $\mathrm{CO}_{2}$ can react again with $\mathrm{C}$ to produce $\mathrm{CO}$, the consequence of previous reaction is the formation of $\mathrm{Fe}$ as an intermediate stage. $\mathrm{Fe}_{2} \mathrm{O}_{3}$ is reduced by $\mathrm{CO}$ to produce $\mathrm{Fe}$. In this work, Fe produced from this reaction is presented in XRD patterns as depicted in figure 2. Then, the intermediate phase $\mathrm{Fe}_{3} \mathrm{Si}$ is formed, which, at the reaction temperature (around $1300^{\circ} \mathrm{C}$ ) $\mathrm{Fe}_{3} \mathrm{Si}$ is in liquid state, where $\mathrm{C}$ dissolved to form a supersaturated solid solution from which the solid phase $\mathrm{SiC}$ is removed (3).

$$
\begin{aligned}
& \mathrm{SiO}_{2}(\mathrm{~s} .1 .)+3 \mathrm{C}(\mathrm{s}) \rightarrow \mathrm{SiC}(\mathrm{s})+2 \mathrm{CO}(\mathrm{g}), \\
& \mathrm{SiO}(\mathrm{g})+2 \mathrm{C}(\mathrm{s}) \leftrightarrow \mathrm{SiC}(\mathrm{s})+\mathrm{CO}(\mathrm{g}), \\
& \mathrm{Fe}\left(\mathrm{Si}^{\mathrm{m}}, \mathrm{C}^{\mathrm{n}}\right) \leftrightarrow \mathrm{SiC}+\mathrm{Fe}\left(\mathrm{Si}^{\mathrm{ml}}, \mathrm{C}^{\mathrm{nl}}\right),
\end{aligned}
$$

where $m_{1}<m$ and $n_{1}<n$.

$\beta$-SiC powder from this synthesis process is also shown in FTIR spectrum as presented in figure 5(b). This figure shows the absorption peak around $902 \mathrm{~cm}^{-1}$ which is caused by bond of $\mathrm{Si}-\mathrm{C}$. Reducing peaks of $\mathrm{SiO}_{2}$ phase in XRD pattern (figure 4) and the last peak FTIR spectrum around $725 \mathrm{~cm}^{-1}$ (figure $5(\mathrm{a})$ ) indicate that $\mathrm{SiO}_{2}$ reacts with another component to produce other phases such as: $\mathrm{SiC}$ or $\mathrm{Fe}_{3} \mathrm{Si}$. Figure 6 shows the morphology of $\beta$-SiC product. This process produces porous $\beta$-SiC micro powder.

\section{Conclusions}

$\beta$-SiC was successfully synthesized at temperature $1300^{\circ} \mathrm{C}$ for $2 \mathrm{~h}$ with starting materials fly ash and $32 \mu \mathrm{m}$ activated carbon powder. There are two reaction mechanisms to produce $\beta$-SiC, that are solid reaction $\mathrm{SiO}_{2}$ and $\mathrm{C}$ and segregation of $\mathrm{SiO}_{2}$ and $\mathrm{C}$ from supersaturated solution of iron. The cycling synthesis process makes new contact point between silicon and carbon and promote the diffusion rate. In this research, $\beta$-SiC was successfully produced and increased by the cycling synthesis.

\section{References}

Hongjie W, Yonglan W and Zhihao J 2001 J. of Mater. Process. Technol. 11752

Joshi R C and Lothia R P 1997 Advances in concrete technology (New York Gordon and Breach Science Publisher) Fly ash in concrete: production, properties and uses, vol. 2

Krstic V D 1992 J. Am. Ceram. Soc. 75170

Narciso-Romero F J and Rodrigues-Reinoso F 1996 J. Mater. Sci. 31779

Qiang Jin G and Yun Go X 2003 Microporous and Mesoporous Mater. 60207

Querol X, Moreno N, Umana J C, Alastuey A, Hernandes E, Lopes-Soler A and Plana F 2002 Int. J. Coal Geol. 50 413

Russell-Floyd R S, Harris B, Cooke RG, Laurie J and Hammett FW 1993 J. Am. Ceram. Soc. 762635

Ryu Z, Zheng J, Wang M and Zhang B 2002 Carbon 40715

Shi L, Zhao H, Yang Y, Li Z and Tan C 2006 Powder Technol. 16971

Sulardjaka, Jamasri, Wildan M W and Kusnanto 2009 MSRI 6 251

Vix-Guterl C and Ehrburger 1997 Carbon 351587

Weimer A W, Nilsen K J, Cochran G A, and Roach R P 1993 AIChE. J. 39493

Woolard CD, Petrus K and van der Horst M 2000 Water 26 531 